\title{
Prevalence, knowledge and perception of self-medication practice among undergraduate healthcare students
}

\author{
Wuraola Akande-Sholabi ${ }^{*}$ (D, Amen. T. Ajamu and Rasaq Adisa
}

\begin{abstract}
Background: Globally, self-medication is a common practice, and an increasingly perceived necessity to relieve burdens on health services. However, inappropriate self-medication may result to reduced health outcomes, increased antimicrobial resistance and economic waste. Healthcare students are the future health professionals who will be consistently responsible for educating the public on rational use of medication. This study therefore aimed to assess the prevalence, knowledge and perception of self-medication practices among healthcare students.
\end{abstract}

Methods: A cross-sectional study was carried out among 866 healthcare students in a Nigerian University, comprising medical, nursing and pharmacy students. Information was garnered from respondents using a self-administered questionnaire. Data were summarized with descriptive statistics, while Chi-square and logistic regression tests were used for categorical variables at $p<0.05$.

Results: Mean age was $21 \pm 2.8$ years, and female respondents were 447 (51.6\%). Prevalence of self-medication among respondents was 473 (54.6\%). A total of 288 (55.3\%) demonstrated good knowledge of self-medication practices, comprising 250 (52.2\%) among those who have previously self-medicated and 229 (47.8\%) among those who had not. Reasons for engaging in self-medication practices were mentioned to include treatment of minor ailments (357; 32.4\%), while 248 (22.5\%) believed they had the medical knowledge of what to use. Analgesic (353; 30.1\%), antimalarial $(352 ; 30.0 \%)$, and antibiotics $(182 ; 15.5 \%)$ were the commonest classes of medication used for self-medication. Headache $(363 ; 18.4 \%)$, malaria $(334 ; 16.9 \%)$, and cough $(184 ; 9.3 \%)$ were the most frequently treated conditions. More than half $(281 ; 59.4 \%)$ of the respondents' purchased their self-medicated drugs from the community pharmacy. Gender and respondents' disciplines were found to be the independent predictors for good knowledge of self-medication practice.

Conclusion: Prevalence of self-medication among the studied healthcare students is moderately high, while approximately half demonstrates good knowledge and perception of self-medication practices. Stimulation for selfmedication practice largely arise from the perception of treating minor ailments. This underscores a need for advocacy on responsible self-medication practice during the formal training of these future health professionals, in order to avert its imminent/widespread negative consequences.

Keywords: Self-medication practice, Antimicrobial resistance, Healthcare students, University undergraduate

*Correspondence: wuradol@gmail.com

Department of Clinical Pharmacy and Pharmacy Administration, Faculty of Pharmacy, University of Ibadan, Ibadan, Nigeria

\section{Introduction}

Globally, self-medication is increasingly being considered as a component of self-care [1]. World Health Organization (WHO) defines self-care as what people original author(s) and the source, provide a link to the Creative Commons licence, and indicate if changes were made. The images or other third party material in this article are included in the article's Creative Commons licence, unless indicated otherwise in a credit line to the material. If material is not included in the article's Creative Commons licence and your intended use is not permitted by statutory regulation or exceeds the permitted use, you will need to obtain permission directly from the copyright holder. To view a copy of this licence, visit http://creativecommons.org/licenses/by/4.0/. The Creative Commons Public Domain Dedication waiver (http://creativeco mmons.org/publicdomain/zero/1.0/) applies to the data made available in this article, unless otherwise stated in a credit line to the data. 
do by themselves to keep their health, prevent and treat illness [2], while International Pharmaceutical Federation [3], supported by World Health Organization [4] defines self-medication (SM) as the self-administration of a medication in the absence of a current prescription and/or without consulting a healthcare professional. Self-medication (SM) with either over-the-counter medications or prescribed medications including antibiotics is a common practice in many developing countries, and partly in some developed countries [5]. The reason(s) for engaging in self-medication practice in developing countries have been reported to include lack of medical insurance, expensive hospitals visits/ consultation fees, easy public access to the prescribed medications [5], suggestions of friends, inexpensiveness of the practice and previous experience [6-9]. Generally, SM is regularly used for minor ailments such as headache, fever, sore throat, gastrointestinal tract problems, respiratory problems, skin disorders, ear symptoms among others [10-15], and WHO recognizes SM as a viable tool for achieving universal health coverage $[16,17]$.

Self-medication could offer several advantages to patients including quick access to treatment, self-independence in alleviating symptoms, reduction in the cost of accessing healthcare and frequency of visits to health centers; and also, to the community, its advantages include saving medical resources, decreasing absence from work, declining pressure on medical services and providing more time for critical conditions [18]. Notwithstanding its various advantages, self-medication, especially if unguided could results into possible risks at the individual level such as incorrect diagnosis, serious adverse effects, increased antimicrobial resistance, dangerous food and drug interactions, as well as drug misuse and abuse. Also, at the community level, unguided selfmedication may lead to increased drug induced disease and public expenses $[18,19]$. The negative consequences of SM can be largely felt in many developing countries with limited resources, low literacy level and healthcare amenities, as well as the huge populace who neither have access to information nor satisfactory knowledge regarding therapy, dosage and duration of use or side effect [18-20]. In Nigeria for instance, the sales of both overthe-counter (OTC) and prescription-only medicine by roadside hawkers, and various unregistered and registered proprietary and patent medicine vendors is common [21], largely because of weak enforcement of drug regulations [22]. The unregulated sales of these products, may incessantly trigger self-medication practice among the general populace. However, a responsible/guided selfmedication may still be envisaged, whereby the patient treat his illness or symptom with medicine which are approved and available without prescription, but which are safe and effective when used as directed [4].

Previous studies have documented that, influencing the prescribing conduct as well as knowledge of the healthcare professionals can encourage responsible self-medication $[6,7,13,14]$. Thus, creating awareness frequently and providing extensive formal training on the concept of responsible self-medication for healthcare students who are the future health professionals may potentially be an efficient approach to circumvent the unwarranted consequences of self-medication. However, to partly achieve this, there may be a need to probe into the knowledge and extent of involvement of healthcare students in selfmedication practices.

Most of the previous studies on self-medication in Nigeria focused on general populations $[8-10,21,23-$ 25], with a paucity of information on healthcare students. Thus, this study aims to assess the prevalence, knowledge and perception of self-medication practices among healthcare students, while the possible reasons for engaging in such practice were also explored.

\section{Methods \\ Study design and setting}

This study was a university-based cross-sectional study using a self-administered questionnaire. It was conducted among undergraduate students at the University of Ibadan, in the Faculty of Pharmacy, Departments of Medicine and Surgery, as well as Nursing, between August and November 2019. Presently in Nigeria, the Bachelor of Pharmacy and Bachelor of Nursing degrees are a 5-year program, while the Bachelor of Medicine and Surgery degree is a 6-year program.

\section{Data collection instrument}

The questionnaire used for this study was designed by the researchers after a thorough review of similar studies $[10,26-28]$, as well as utilizing researchers' proficiency. The questionnaire comprised three sections. Section A evaluated socio-demographic characteristics of the students such as age, gender, level of study and course of study. Section B consisted of questions on students' level of knowledge and perception on self-medication, while Section C consisted of questions on the participants' practice of self-medication. The questions were evaluated on a 5-point Likert rating scale from strongly agree (5) to strongly disagree (1) to explore and evaluate students' knowledge and perception of self-medication practice. The overall score for the knowledge and perception questions were categorized into 'good' and 'poor' depending on respondents' score in each domain. For the 8-item statements on knowledge with 5-point Likert scale response, a total score of at least $32(\geq 80 \%)$ 
out of the maximum obtainable score of 40 was categorized as 'good' knowledge, while a knowledge score $<32$ $(<80 \%)$ was categorized as 'poor' knowledge. For the 3-item statements on perception with 5-point Likert scale response, a total score of at least $12(\geq 80 \%)$ out of the maximum obtainable score of 15 was categorized as 'good' perception, while a score $<12$ was categorized as 'poor' perception. The binary categorization of knowledge and perception scores was adapted from Bloom's cut-off criteria and other similar studies [29-31].

\section{Inclusion and exclusion criteria}

Eligible participants were registered undergraduate students of Medicine and Surgery, Pharmacy and Nursing, for the 2018/2019 academic session. Participants must have also given voluntary informed consent to partake in the study. Students who were absent in the classes during the period of questionnaire administration, as well as the non-consenting individuals were excluded.

\section{Sample size determination}

Based on the population of 1521 registered students for the 2018/2019 academic session, comprising Pharmacy (360), Medicine and Surgery (881), and Nursing (280) at 95\% confidence level and 5\% alpha error, a sample size of 316 was obtained using Yamane's formula [32]. Additionally, to cater for the possibility of a low response rate, which is not uncommon among students, an attrition rate close to $200 \%$ was allowed.

\section{Sampling and data collection procedure}

Students were approached after a major lecture identified across the levels in each faculty/departments, purpose and objectives of the study were explained to the students immediately at the end of the identified major classes. Each questionnaire, which took about $12-15 \mathrm{~min}$ to be completed was subsequently administered only to the consented individuals. This was done in the period allocated for questionnaire administration for each Faculty or Department. The questionnaires were retrieved after completion and inspected for completeness and correctness. Study participation was voluntary and the students were informed of the possibility of withdrawing from the study anytime. Response anonymity and confidentiality were reiterated to the respondents. Measures were put in place to prevent multiple filling of the questionnaire by the respondents. This was achieved by coding each questionnaire administered to the students from each department to avoid duplication.

\section{Pretest and content validation}

Content validity was established by three scholars with expertise in the subject area, to ascertain the inclusiveness of question-items in line with the objectives of the study. Thereafter, pretest was carried out by administering the questionnaire to thirty students randomly selected from the Pharmacy, Nursing, and Medical and Surgery departments. These students were exempted from the main study. Feedback from these students on clarity of the questions or statements in the questionnaire led to some modifications in the questionnaire, such as significant reduction in the number of open-ended questions.

\section{Statistical analysis}

Data were coded, cleaned, and analyzed using the IBM Statistical Package for Social Sciences (version 23). Descriptive statistics such as frequency, percentages, mean, and standard deviation were used to summarize the data. The internal consistency/reliability of the 11-items self-medication knowledge and perception questions was determined using Cronbach alpha test, with a value of 0.68 . Association between demographic variables and respondents' engagement in self-medication practice or not was evaluated with Chi-square, while binary logistic regression was used to ascertain the predictors of good or poor knowledge and perception on self-medication practice. The level of significance was set at $p<0.05$.

\section{Results}

\section{Demographic characteristics of respondents}

Of the 960 copies of questionnaires distributed among the respondents, 866 were completed and included in the analysis given a response rate of $90.2 \%$. This comprised, Medicine and Surgery (436; 50.3\%), Pharmacy $(275 ; 31.8 \%)$ and Nursing $(155 ; 17.9 \%)$ students. Mean age was $21 \pm 2.8$ years, and 447 (51.6\%) were females. The prevalence of self-medication practice was highest among females $(261 ; 58.4 \%)$ and students aged $>20$ years (259; 56.2\%). Also, self-medication practice among the healthcare students was in the order of Medicine and Surgery $(259 ; 59.4 \%)>$ Nursing $(78 ; 50.3 \%)>$ Pharmacy (136; 49.5\%), $p=0.017$. Year 5 and Year 6 students constituted those who had largely engaged in self-medication, $116(63.0 \%)$ and $44(81.5 \%)$, respectively $(p=0.000)$. In all, the prevalence of self-medication practice among the respondents was 473 (54.6\%) (Table 1$)$.

\section{Knowledge and perception about self-medication practice among respondents}

Table 2 shows the assessment of respondents' knowledge and perception on the practice of self-medication. A total of $479(55.3 \%)$ had score $\geq 80 \%$ indicating 'good' knowledge; comprising 250 (52.2\%) among those who had self-medicated and $229(47.8 \%)$ among those who had 
Table 1 Distribution of respondents demographic characteristics based on the practice of self-medication $(n=866)$

\begin{tabular}{|c|c|c|c|c|}
\hline Variable & $\begin{array}{l}\text { Engagement in self-medication, YES } n \\
(\%) n=473(54.6)\end{array}$ & $\begin{array}{l}\text { No self-medication } n(\%) \\
n=393(45.4)\end{array}$ & Chi-square & $p$-value \\
\hline \multicolumn{5}{|l|}{ Gender } \\
\hline Male & $212(50.6)$ & $207(49.4)$ & 5.298 & $0.021 *$ \\
\hline Female & $261(58.4)$ & $186(41.6)$ & & \\
\hline \multicolumn{5}{|l|}{ Age (year) } \\
\hline$\leq 20$ & $214(52.8)$ & $191(47.2)$ & 4.193 & 0.123 \\
\hline$>20$ & $259(56.2)$ & $201(43.8)$ & & \\
\hline \multicolumn{5}{|l|}{ Department } \\
\hline Nursing & $78(50.3)$ & 77 (49.7) & 8.14 & $0.017^{*}$ \\
\hline Pharmacy & $136(49.5)$ & $139(50.5)$ & & \\
\hline Medicine and surgery & $259(59.4)$ & $177(40.6)$ & & \\
\hline \multicolumn{5}{|l|}{ Year of study } \\
\hline Year 1 & $62(49.6)$ & $63(50.4)$ & 33.631 & $0.000 *$ \\
\hline Year 2 & $66(51.2)$ & $63(48.8)$ & & \\
\hline Year 3 & $105(56.1)$ & $82(43.9)$ & & \\
\hline Year 4 & $80(42.8)$ & $107(57.2)$ & & \\
\hline Year 5 & $116(63.0)$ & $68(37.0)$ & & \\
\hline Year 6 & 44 (81.5) & 10 (18.5) & & \\
\hline
\end{tabular}

*Statistically significant $(p<0.05)$

not. Over half $(223 ; 57.6 \%)$ of the respondents who had self-medicated constituted those with 'poor' knowledge compared to those who had not $(164 ; 42.4 \%)$. Moreover, a total of $584(67.4 \%)$ had score $\geq 80 \%$ indicating 'good' perception. There was no statistically significant difference among respondents who had either self-mediated or not in respect of knowledge $\left(\chi^{2}=2.547 ; p=0.111\right)$ and perception $\left(\chi^{2}=0.020 ; p=0.887\right)$.

\section{Determinants of knowledge and perception} on self-medication practice among the respondents Gender and respondents' disciplines were found to be independent predictors of good knowledge. Females were 1.4 times more knowledgeable about self-medication (AOR: 1.43 [CI: 1.059-1.953], $p=0.02$ ) than males. However, students of Pharmacy had lower odds for knowledge (AOR: 0.621 [CI: 0.401-0.961], $p=0.03$ ), and perception (AOR: 0.577 [CI: 0.365-0.913], $p=0.019$ ) on self-medication practice than the students of Nursing and Medicine and Surgery. Details are in Table 3.

\section{Reasons for engaging in self-medication practice by respondents}

The arrays of reasons for engaging in self-medication practice are presented in Table 4. The majority, 357 (32.4\%) engaged in the practice for treatment of minor ailments, while 248 (22.5\%) believed they had the medical knowledge of what to use and $122(11.1 \%)$ did not want to waste time at the clinic. Other reasons cited included previous experience from old prescriptions (81; $7.3 \%)$, inability to afford laboratory investigation costs (66; 6.0\%), as well as left-over medications (61; 5.5\%) (Table 4).

\section{Medications used for self-medication practice and the conditions treated}

Analgesic, 353 (30.1\%) was the most commonly used class of medication, followed by antimalarial (352; 30.0\%), antibiotics (182; 15.5\%) and multivitamins, 142 (12.1\%). The most frequently treated conditions by self-medication among respondents were headache (363; 18.4\%), malaria $(334 ; 16.9 \%)$, cough $(184 ; 9.3 \%)$, menstrual pain (170; $8.6 \%)$ and cold and flu $(158 ; 8.0 \%)$. Details are in Table 5.

\section{Source of medications and information on drug dosage regimen for self-medication practice}

More than half $(281 ; 59.4 \%)$ of the respondents' purchased their medications from the community pharmacy, followed by proprietary and patent medicine vendor (116; 24.5\%), and friends/family (48; 10.1\%). Twentyeight (5.9\%) reported to have their medications from the hospital, perhaps representing those who reuse medication from left over of previously prescribed medications. Patient information leaflet $(251 ; 32.3 \%)$ was the commonest source of information about dosage and duration of medications, followed by family and friends (172; $22.1 \%)$ and classroom/lectures 143 (18.4\%) (Table 6). 


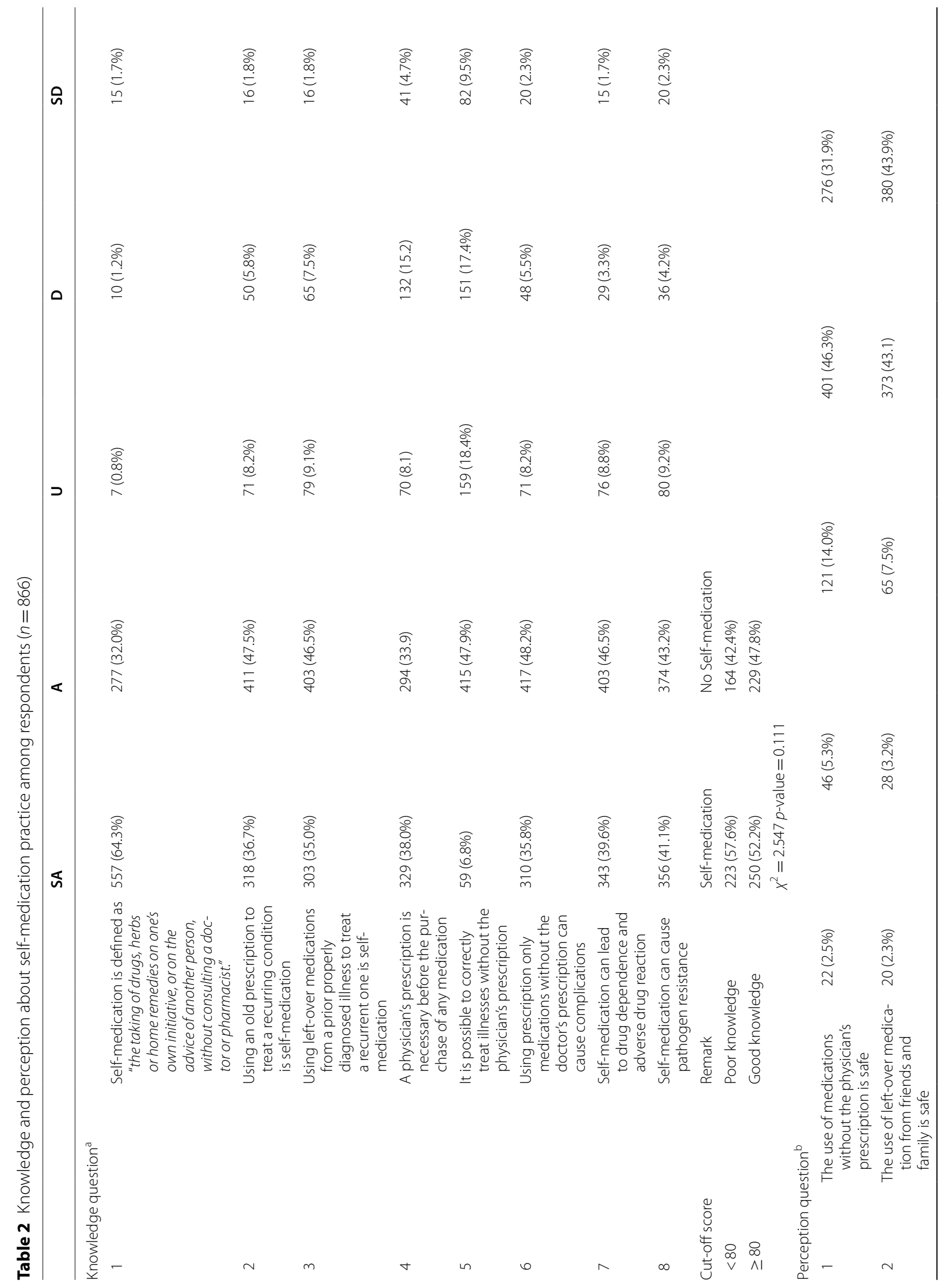




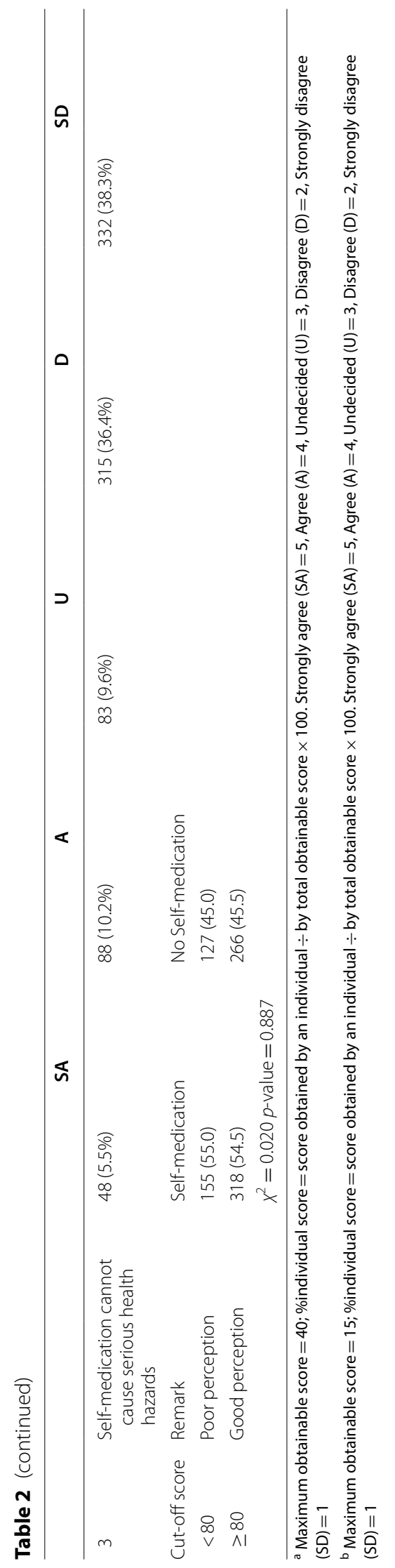


Table 3 Determinants of knowledge and perception of self-medication practice among respondents $(n=866)$

\begin{tabular}{|c|c|c|c|c|c|c|}
\hline \multirow[t]{2}{*}{ Variables } & \multicolumn{2}{|c|}{ Knowledge on self-medication } & \multicolumn{2}{|c|}{ Unadjusted odds ratio } & \multicolumn{2}{|l|}{ Adjusted odds ratio } \\
\hline & Good (\%) & Poor (\%) & OR $(95 \% \mathrm{Cl})$ & $p$-value & OR $(95 \% \mathrm{Cl})$ & $p$-value \\
\hline \multicolumn{7}{|l|}{ Gender } \\
\hline Male & $214(51.1)$ & $205(48.9)$ & 1 & $0.015^{*}$ & & $0.020^{*}$ \\
\hline Female & $265(59.3)$ & $182(40.7)$ & $1.395(1.066-1.825)$ & & $1.431(1.059-1.935)$ & \\
\hline \multicolumn{7}{|l|}{ Age-group (years) } \\
\hline$\leq 20$ ref & $223(55.1)$ & $182(44.9)$ & 1 & 0.890 & & 0.642 \\
\hline$>20$ & $256(55.5)$ & $205(44.5)$ & 1.019 (0.779-1.333) & & $0.909(0.607-1.361)$ & \\
\hline \multicolumn{7}{|l|}{ Department } \\
\hline Nursing ref & $97(62.6)$ & $58(37.4)$ & 1 & & & \\
\hline Pharmacy & $135(49.1)$ & $140(50.9)$ & $0.577(0.386-0.862)$ & $0.007^{*}$ & $0.621(0.401-0.961)$ & $0.033^{*}$ \\
\hline Medicine and surgery & $247(56.7)$ & $189(43.3)$ & $0.781(0.536-1.139)$ & 0.199 & $1.046(0.685-1.598)$ & 0.834 \\
\hline \multicolumn{7}{|l|}{ Year of study } \\
\hline Year 1 & $69(55.2)$ & $56(44.8)$ & 1 & & 1 & \\
\hline Year 2 & $72(55.8)$ & $57(44.2)$ & $1.025(0.625-1.682)$ & 0.922 & $0.989(0.593-1.650)$ & 0.966 \\
\hline Year 3 & $93(49.7)$ & $94(50.3)$ & $0.803(0.510-1.265)$ & 0.344 & $0.781(0.488-1.251)$ & 0.304 \\
\hline Year 4 & $117(62.6)$ & $70(37.4)$ & $1.357(0.856-2.150)$ & 0.194 & $1.624(0.950-2.775)$ & 0.076 \\
\hline Year 5 & $103(56.0)$ & $81(44.0)$ & $1.032(0.653-1.630)$ & 0.892 & $1.244(0.692-2.236)$ & 0.466 \\
\hline \multirow[t]{3}{*}{ Year 6} & $25(46.3)$ & $29(53.7)$ & $0.274(0.700-1.328)$ & 0.274 & $0.691(0.321-1.485)$ & 0.344 \\
\hline & \multicolumn{2}{|c|}{ Perception on self-medication } & \multicolumn{2}{|c|}{ Unadjusted odds ratio } & \multicolumn{2}{|l|}{ Adjusted odds ratio } \\
\hline & Good (\%) & Poor (\%) & OR $(95 \% \mathrm{Cl})$ & $p$-value & OR $(95 \% \mathrm{Cl})$ & $p$-value \\
\hline \multicolumn{7}{|l|}{ Gender } \\
\hline Male & $282(67.3)$ & $137(32.7)$ & 1 & 0.935 & & 0.780 \\
\hline Female & $302(67.6)$ & $145(32.4)$ & $1.012(0.761-1.345)$ & & $0.956(0.697-1.312)$ & \\
\hline \multicolumn{7}{|l|}{ Age-group (years) } \\
\hline$\leq 20$ ref & $278(68.6)$ & $127(31.4)$ & 1 & 0.478 & & 0.232 \\
\hline$>20$ & $306(66.4)$ & $155(33.6)$ & $0.902(0.678-1.200)$ & & $0.772(0.506-1.179)$ & \\
\hline \multicolumn{7}{|l|}{ Department } \\
\hline Nursing ref & $111(71.6)$ & $44(28.4)$ & 1 & & & \\
\hline Pharmacy & $165(60.0)$ & $110(40.0)$ & $0.595(0.389-0.909)$ & $0.016^{*}$ & $0.577(0.365-0.913)$ & $0.019^{*}$ \\
\hline Medicine and surgery & $308(70.6)$ & $128(29.4)$ & $0.954(0.636-1.431)$ & 0.819 & $0.958(0.611-1.500)$ & 0.850 \\
\hline \multicolumn{7}{|l|}{ Year of study } \\
\hline Year 1 & $88(70.4)$ & $37(29.6)$ & 1 & & 1 & \\
\hline Year 2 & $88(68.2)$ & 41(31.8) & $0.902(0.529-1.539)$ & 0.706 & $0.829(0.480-1.433)$ & 0.502 \\
\hline Year 3 & $120(64.2)$ & $67(35.8)$ & $0.753(0.463-1.225)$ & 0.253 & $0.740(0.449-1.220)$ & 0.238 \\
\hline Year 4 & $131(70.1)$ & $56(29.9)$ & $0.984(0.599-1.614)$ & 0.948 & $1.226(0.694-2.165)$ & 0.483 \\
\hline Year 5 & $115(62.5)$ & $69(37.5)$ & $0.701(0.431-1.140)$ & 0.152 & $0.895(0.484-1.656)$ & 0.725 \\
\hline Year 6 & $12(22.2)$ & $42(77.8)$ & $1.472(0.697-3.108)$ & 0.311 & $1.582(0.669-3.742)$ & 0.297 \\
\hline
\end{tabular}

*Statistically significant $(p<0.05) \mathrm{Cl}$ confidence interval

\section{Discussion}

In this study, we investigated the prevalence of selfmedication as well as the knowledge and perception towards self-medication practice among healthcare students in a Nigerian University. This was done to better understand the extent of this practice among the cohort, while exploring the reasons that drives or encourages such practice. Our findings reveal a moderately high prevalence $(54.6 \%)$ of self-medication practice across the three major disciplines of healthcare students studied. The moderately high rate of self-medication practice is consistent with previous studies across different countries, which focus largely on university students and the general population $[6-9,11-15,21,23,24,26$, $27,33,34]$. The variation in self-medication practice among countries might be attributed to the differences in 
Table 4 Summary of respondents' reasons for engaging in self-medication practice

\begin{tabular}{lll}
\hline Reasons for self-medication $(\boldsymbol{n = 1 1 0 3 )}$ & Frequency & Percentage (\%) \\
\hline Treatment of minor ailment & 357 & 32.4 \\
I have medical knowledge of what to use & 248 & 22.5 \\
I do not want to waste time at the clinic & 122 & 11.1 \\
I know what to use from old prescription & 81 & 7.3 \\
I cannot afford laboratory fees & 66 & 6.0 \\
I had left-over medication & 61 & 5.5 \\
The healthcare facility is far from my place of abode & 54 & 4.9 \\
The pain was severe & 48 & 4.4 \\
I cannot wait for laboratory results & 37 & 3.4 \\
I cannot afford consultation fees & 29 & 2.5 \\
\hline
\end{tabular}

${ }^{\text {a }}$ Multiple response

Table 5 Summary of medications used for self-medication and conditions treated by self-medication practice $(n=473)$

\begin{tabular}{|c|c|c|}
\hline Variable & Frequency & Percentage (\%) \\
\hline \multicolumn{3}{|c|}{${ }^{a}$ Class of medication used for self-medication $(n=1172)$} \\
\hline Analgesic & 353 & 30.1 \\
\hline Antimalarial & 352 & 30.0 \\
\hline Antibiotics & 182 & 15.5 \\
\hline Multivitamins & 142 & 12.1 \\
\hline Antihistamine & 115 & 9.8 \\
\hline Slimming pills & 19 & 1.6 \\
\hline Others & 9 & 0.9 \\
\hline \multicolumn{3}{|c|}{ 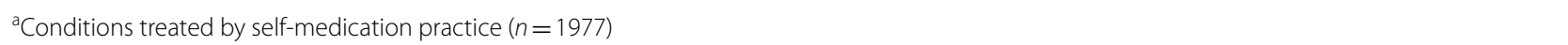 } \\
\hline Headache & 363 & 18.4 \\
\hline Malaria & 334 & 16.9 \\
\hline Cough & 184 & 9.3 \\
\hline Menstrual pain & 170 & 8.6 \\
\hline Cold and flu & 158 & 8.0 \\
\hline Fever & 143 & 7.2 \\
\hline Sore throat & 141 & 7.1 \\
\hline Diarrhea & 113 & 5.7 \\
\hline Stomachache & 105 & 5.3 \\
\hline Constipation & 73 & 3.7 \\
\hline Skin infections & 71 & 3.6 \\
\hline Vomiting & 34 & 1.7 \\
\hline Infections (toothache, STDs and UTI) & 29 & 1.5 \\
\hline Eye problem & 28 & 1.4 \\
\hline Ear problem & 21 & 1.1 \\
\hline Ulcer & 4 & 0.2 \\
\hline Rhinitis & 2 & 0.1 \\
\hline Toothache & 2 & 0.1 \\
\hline Sinusitis & 1 & 0.05 \\
\hline Nausea & 1 & 0.05 \\
\hline
\end{tabular}


Table 6 Source of information on dosage regimen and medications for self-medication practice

\begin{tabular}{lcc}
\hline Variable & Frequency & Percentage (\%) \\
\hline Source of medication $(n=473)$ & & \\
Community pharmacy & 281 & 59.4 \\
Patent medicine vendor & 116 & 24.5 \\
Friends/family & 48 & 10.2 \\
Hospital & 28 & 5.9 \\
aSource of information on drug dosage regimen $(n=777)$ \\
Patient Information leaflet & 251 & 32.3 \\
Family and friends & 172 & 22.1 \\
Classroom & 143 & 18.4 \\
Textbook & 132 & 16.9 \\
Social media & 52 & 6.7 \\
Print media (newspaper and magazine) & 27 & 3.6 \\
\hline
\end{tabular}

${ }^{a}$ Multiple response

demographic characteristics and socioeconomic factors of respondents [6-9, 11-15, 21, 23, 24, 26, 27, 33, 34].

Of note, the self-medication practice was highest among female healthcare students compared to their male counterparts, which perhaps correlate with previous studies [10-13]. The gender difference in self-medication practice among the respondents might possibly be linked to the propensity of the females to engage in self-recommendation of analgesic group of medications to relieve pains and symptoms during their monthly menstrual cycle. Analgesics are the most commonly recommended medicines for the relief of menstrual pain in women, and as reflected in this study, menstrual pain is one of the top five conditions treated by self-medication.

In addition, 5th year Nursing and Pharmacy students, as well as Medicine and Surgery students constitute respondents who mostly engaged in self-medication practice. Generally, in the curriculum for the healthcare students at the 5th year, students are expected to have gained substantial knowledge in disease management, while they would have also been involved in direct patient care and management at one point or the other during their mandatory clinical rotations and exposure. Perhaps, this could have accounted for the perceived confidence in managing minor ailments by the respondents, as well as believe that they have acquired the requisite medical knowledge of what to use for a particular condition treated. Even though, 'learning by doing' is an encouraging concept that is consistently advocated in the training of healthcare students. However, for this approach to achieve the intended goal, it should be done responsibly, especially under the tutelage and guidance of senior and qualified clinical instructors/tutors in their respective disciplines. Otherwise, the act may lead to avoidable risk that self-medication could pose to future healthcare professionals. Previous studies have also documented that healthcare students tend to self-medicate probably owing to believe that they have the knowledge of what to use [6, $7,12,14]$.

In the present study, it is observed that pharmacy students engaged least in self-medication, compared to their counterparts in Nursing and Medicine, this variation in the engagement of self-medication could be as a result of pharmacy student knowing more about the risks of selfmedication. Furthermore, female respondents, as well as nursing and medical students had higher odds of knowledge of self-medication practice than their other counterparts. Similarly, nursing and medical students had higher odds of perception of self-medication than the pharmacy students. Typically, one who have expected pharmacy students to have higher odds of knowledge and perception of self-medication than their nursing and medical students' counterparts, mainly because they are largely going to be the future custodian of medicines, thus they should possess more knowledge of self-medication. This gap perhaps suggests a need to further look into the training curriculum of the healthcare students in general, and the pharmacy students in particular. This is in a bid to consider incorporation of relevant components of selfmedication concept that will prepare the students for the future roles and responsibilities as a medicine expert.

Noteworthy to mention that the main source for purchasing medications for self-medication practices by respondents is the community pharmacies, followed by patent medicine vendors, while the left-over medicines at home, from friends and families were also mentioned. Hence, the need for appropriate government authorities specifically National Agency for Food Drug Administration and Control (NAFDAC) and the Pharmacists Council of Nigeria (PCN), to take necessary steps in ensuring consistent enforcement of medicine regulation as well as public enlightenment of responsible self-medication. On the other hand, community pharmacists especially should consistently uphold the ethics of the pharmacy profession by ensuring that only the clients who genuinely need a medicine obtain the product with proper guidance/instruction on rational usage. Our study is perhaps the first study in Nigeria to comprehensively evaluate self-medication practice among the healthcare students, while concurrently attempting to clarify the likely motivating reasons driving these practices, hence a major strength of the study.

Aside from analgesics as the most prevalent medication category used for self-medication, antimalarial and antibiotics were also part of the topmost medications used to self-medicate by respondents. This is not surprising, and can be supported by the fact that headache, malaria, 
cough, menstrual pain, cold and flu were the most frequently treated conditions by the respondents. Findings from previous studies also reported that analgesics and antipyretic are the most prevalent medication categories used for self-medication [7, 12, 15, 28, 35], Ideally, antibiotics and antimalarial should not be sold without a prescription from a qualified medical practitioner/physician as practiced in most developed countries and some developing countries. However, this is contrary to the situation in Nigeria, where most antimalarial and antibiotics may be purchased over-the-counter from medicine vendors without a prescription, and some community pharmacies are also inclusive. The weak enforcement of medicine regulations, as well as public easy accessibility to prescription-only medicine needs to be addressed by the appropriate authorities in order to prevent potential harm(s). Previous studies have reported that between $52.2 \%$ and $55 \%$ of Nigerian population obtained their medicines for self-medication practice from the patent medicine stores [23, 24], where they do not have the opportunity of accessing relevant and appropriate counselling services to guide medication usage [36, 37].

Our study also reveals that patient information leaflet is topmost of the common sources of information on dosage regimen for medicines used for self-medication practice. This may be expected since most of the respondents are more likely to be aware that patient information leaflet or the manufacturer's literature insert serves as a quick and most readily available source of information for pharmaceutical products, though sometimes, manufacturer's bias may distort/affect the reliability of information from such package insert.

\section{Limitation of the study}

This study is limited by the possibility of recall bias, which is most inherent in self-report study of this nature. Also, the likelihood of respondents discussing among themselves while filling the questionnaire may not be totally excluded, being a self-administered questionnaire. In addition, future study may still need to consider other possible indicators aside from knowledge and perception as well as factors that may influence future healthcare professional especially pharmacy students in engaging in responsible self-medication practice. The above-mentioned gaps may therefore need to be considered in order to ensure a far-reaching conclusion, while caution should be exercised in generalizing the study findings to the entire population of healthcare students in the region.

\section{Conclusion}

Prevalence of self-medication among the studied healthcare students is moderately high, while approximately half demonstrates good knowledge and perception of self-medication practices. Gender and respondents' discipline were the notable independent predictors of good knowledge of self-medication, while stimulation for selfmedication practice largely arise from the perception of treating minor ailments. This generally underscores a need for relevant advocacy and incorporation of aspects of responsible self-medication practice during the formal training of these future healthcare professionals. In addition, national guideline on medicine access should be reenforced, with strong measures put in place to implement the policy, this may become necessary in order to avert the widespread negative consequences of self-medication practice among the populace generally.

\section{Abbreviations}

NAFDAC: National Agency for Food and Drug Administration and Control; OTC: Over the counter; PCN: Pharmacist Council of Nigeria; WHO: World Health Organization.

\section{Acknowledgements}

We would like to express our appreciation to the students who accepted to participate and dedicated their time to fill the questionnaire.

\section{Authors' contributions}

We declare that this work was done by the author(s) named in this article. Wuraola Akande-Sholabi (WAS) conceived the idea, WAS and Amen T Ajamu (ATA) designed the study, contributed in data acquisition, performed data analysis and interpretation. WAS drafted the manuscript. RA revised the manuscript. All authors contributed to the preparation of the manuscript, read and approved the final version.

\section{Funding}

No specific Grant from any funding agency in the public, commercial or notfor-profit sector was received in carrying out this study.

\section{Availability of data and materials}

The datasets used and/or analyzed during the current study are available from the corresponding author on reasonable request.

\section{Declarations}

Ethics approval and consent to participate

Ethics approval for the study was obtained from the joint University of Ibadan/ University College Hospital Institution Review Board with approval number UI/ EC/19/0403. Verbal informed consent in accordance with the approved study protocol by the Ethics committee was obtained from individual student after explaining the objectives and procedure of the study to participant individually. Verbal informed consent was deemed appropriate for our study being a questionnaire-based survey with questions carefully designed without infringement on participants' privacy. Only the consented participants within the study period were enrolled.

Consent for publication

Not applicable.

Competing interests

The authors declare that they have no competing interests.

Received: 8 December 2020 Accepted: 7 June 2021

Published online: 10 June 2021 


\section{References}

1. James H, Handu SS, Khalid AJ, Khaja AL, Otoom S, Sequeira RP. Evaluation of knowledge, attitude and practice of self-medication among first year medical student. Med Princ Pract. 2006;15:270-5.

2. World Health Organization. Guidelines for the regulatory assessment of medicinal products for use in self-medication; 2000 https://apps.who.int/ medicinedocs/fr/d/Js2218e/ (Accessed May 6th, 2021).

3. International Pharmaceutical Federation. Joint statement by the International Pharmaceutical Federation and The World Self-Medication Industry; 1999 [Available from: https://www.fip.org (Accessed May $8^{\text {th }}$, 2021)

4. World Health Organization. The role of the pharmacist in selfcare and self-medication. Report of the 4th WHO consultative Group on the role of the pharmacist; 1998. https://app.who.int/iris/bitstream/handle/10665/ 65 (Accessed 10th May 2021)

5. Shaghaghi A, Asadi M, Allahverdipour H. Predictors of self-medication behavior: a systematic review. Iran J Public Health. 2014;43(2):136-46.

6. Lukovic JA, Miletic V Pekmezovic T, Trajkovic G, Ratkovic N, Aleksic D, Grgurevic A. Self-medication practices and risk factors for selfmedication among medical students in Belgrade, Serbia. PLoS ONE. 2014;9(12):e114644. https://doi.org/10.1371/journal.pone.0114644.

7. Araia ZZ, Gebregziabher NK, Mesfun AB. Self medication practice and associated factors among students of Asmara College of Health Sciences, Eritrea: a cross sectional study. J Pharm Policy Practice. 2019;12:3. https:// doi.org/10.1186/s40545-019-0165-2.

8. Brieger WR, Ramakrishna J, Adeniyi JD. Self-treatment in rural Nigeria: a community health education diagnosis. Int J Health Educ. 1986;5:2-6.

9. Bamigboye EA, Amoran OE, Yusuff OB. Self medication practices among workers in a tertiary hospital in Nigeria. Afr J Med Med Sci. 2006:35:411-5.

10. Babatunde OA, Fadare JO, Ojo OJ, Durowade KA, Atoyebi OA, Ajayi PO, Olaniyan T. Self-medication among health workers in a tertiary institution in South-West Nigeria. Pan Afr Med J. 2016;24:1-8. https://doi.org/10. 11604/pamj.2016.24.312.8146.

11. Gelayee DA. Self-medication pattern among social science university students in Northwest Ethiopia, De Simone G, editor. J Pharm. 2017;2017:8680714. https://doi.org/10.1155/2017/8680714.

12. Kumar N, Kanchan T, Unnikrishnan B, Rekha T, Mithra P, Kulkarni V, Papanna MK, Holla R, Uppal S. Perceptions and practices of selfmedication among medical students in coastal South India. PLoS ONE. 2013;8(8):e72247. https://doi.org/10.1371/journal.pone.0072247.

13. Helal RM, Abou-Elwafa HS. Self-medication in University students from the city of Mansoura. Egypt J Environ Public Health. 2017. https://doi.org/ 10.1155/2017/9145193

14. Abay SM, Amelo W. Assessment of self-medication practices among medical, pharmacy, and health science students in Gondar University. Ethiopia J Young Pharm. 2010;2:306-10. https://doi.org/10.4103/09751483.66798

15. Ahmadi SM, Jamshidi K, Sadeghi K, Abdi A, Vahid MP. The prevalence and affecting factors on self-medication among students of Kermanshah University of medical sciences. J Clin Diagn Res. 2016. https://doi.org/10. 7860/JCDR/2016/18018.7847.

16. Papakosta M, Zavras D, Niakas D. Investigating factors of self-care orientation and self-medication use in a Greek rural area. Rural Remote Health. 2014;14:2349

17. WHO. WHO library cataloguing-in-publication data global action plan on antimicrobial resistance. Vol. 10, Microbe Magazine (online). 2015; www. paprika-annecy.com (cited 2020 Aug 28).

18. Bown D, Kisuule G, Ogasawara H, Siregar C, Williams G. WHO guidelines for the regulatory assessment of medicinal products for use in self medication. WHO Drug Inf. 2000;14:18-26.

19. Bennadi D. Self-medication: a current challenge. J Basic Clin Pharm. 2014:5:19-23.
20. Chouhan K, Prasad SB. Self-medication and their consequences: a challenge to health professional. Asian J Pharm Clin Res. 2016;9:314-7.

21. Uzochukwu BS, Onwujekwe OE, Okwuosa C, Ibe OP. Patent medicine dealers and irrational use of medicines in children: the economic cost and implications for reducing childhood mortality in Southeast Nigeria. PLOS ONE. 2014;9(3):91667.

22. Erhun W, Babalola OO. Drug regulation and control in Nigeria: the challenge of counterfeit drugs. World Health Popul. 2013. https://doi.org/10 12927/WHP.17597.

23. Afolabi AO. Factors influencing the pattern of self-medication in an adult Nigerian population. Ann Afr Med. 2008;7:120-7.

24. Yusuff KB, Omarusehe LD. Determinants of self-medication practices among pregnant women in Ibadan, Nigeria. Int J Clinical Pharmacy. 2011;33:868-75. https://doi.org/10.1007/s/11096-011-9556-4.

25. Osemene KP, Lamikanra A. A study of the prevalence of self-medication practice among university students in south western Nigeria. Trop J Pharm Res. 2012;11:683-9. https://doi.org/10.4314/tjpr.v11i4.21.

26. Abdi A, Faraji A, Dehghan F, Khatony A. Prevalence of self-medication practice among health sciences students in Kermanshah, Iran. BMC Pharmacol Toxicol. 2018:19:36. https://doi.org/10.1186/s40360-018-0231-4.

27. Alkhatatbeh MJ, Alefan Q, Alqudah MA. High prevalence of self-medication practices among medical and pharmacy students: a study from Jordan. Int J Clin Pharmacol Ther. 2016;54:390-8. https://doi.org/10.5414/ CP202451.

28. Albusalih FA, Naqvi AA, Ahmad R, Ahmad N. Prevalence of self-medication among students of pharmacy and medicine colleges of a public sector University in Dammam City, Saudi Arabia. Pharmacy. 2017:5:51. https://doi.org/10.3390/pharmacy5030051.

29. Blooms BS, ed. Taxonomy of educational objectives: the classification of Educational Goals, Handbook I, Cognitive Domain. London: Longmans, Green; 1956.

30. Akande-Sholabi W, Adisa R, llesanmi OS, Bello AE. Extent of misuse and dependence of codeine-containing products among medical and pharmacy students in a Nigerian University. BMC Public Health. 2019;19:1709. https://doi.org/10.1186/s12889-019-8074-5.

31. Akande-Sholabi W, Ogundipe FS, Adisa R. Pharmacists' knowledge and counselling on fall risk increasing drugs in a tertiary teaching hospital in Nigeria. BMC Health Serv Res. 2020;20:259.

32. Yamane T. Statistics, an introductory analysis. 2nd ed. New York: Harper and Rao; 1967. p. 886

33. Omolase CO, Adeleke OE, Afolabi AO, Ofolabi OT. Self medication amongst general outpatients in a Nigerian community hospital. Ann Ibadan Postgrad Med. 2007;5:64-7.

34. Afolabi AO, Akinmoladun VI, Adebose IJ, Elekwachi G. Self-medication profile of dental patients in Ondo State, Nigeria. Niger J Med J Natl Assoc Resid Dr Niger. 2010;19:96-103. https://doi.org/10.4314/njm.v19i1.52488.

35. Gras M, Champel V, Masmoudi K, Liabeuf S. Self-medication practices and their characteristics among French university students. Therapies. 2020. https://doi.org/10.1016/j.therap.2020.02.019.

36. Brieger WR, Osamor PE, Salami KK, Oladepo O, Otusanya SA. Interactions between patent medicine vendors and customers in urban and rural Nigeria. Health Policy Plan. 2004;19:177-82.

37. Adikwu MU. Sales practices of patent medicine sellers in Nigeria. Health Policy Plan. 1996;11:202-3.

\section{Publisher's Note}

Springer Nature remains neutral with regard to jurisdictional claims in published maps and institutional affiliations. 